\title{
A Case of Mucoepidermoid Carcinoma Mixed with Osteosarcoma of the Parotid Gland Extending to the Parapharyngeal Space
}

\author{
Hyun-Keun Kwon ${ }^{1} \mathbb{D}$, Sung-Chan Shin ${ }^{1} \mathbb{D}$, Jin-Choon Lee ${ }^{2} \mathbb{D}$, and Byung-Joo Lee ${ }^{1} \mathbb{D}$ \\ ${ }^{I}$ Department of Otorhinolaryngology-Head and Neck Surgery, Pusan National University Hospital, Busan; and \\ ${ }^{2}$ Department of Otorhinolaryngology-Head and Neck Surgery, Pusan National University Yangsan Hospital, Yangsan, Korea
}

\author{
이하선에서 부인두 공간까지 확장된 골육종과 혼합된 점액표피암종 1 예 \\ 권현근 $^{1} \cdot$ 신성찬 $^{1} \cdot$ 이진춘 $^{2} \cdot$ 이병주 ${ }^{1}$ \\ 부산대학교병원 이비인후과, ${ }^{1}$ 양산부산대학교병원 이비인후과 ${ }^{2}$
}

\author{
Received September 14, 2018 \\ Revised November 15, 2018 \\ Accepted November 29, 2018 \\ Address for correspondence \\ Byung-Joo Lee, MD, PhD \\ Department of Otorhinolaryngology- \\ Head and Neck Surgery, \\ Pusan National University Hospital, \\ 179 Gudeok-ro, Seo-gu, \\ Busan 49241, Korea \\ Tel $+82-51-240-7335$ \\ Fax $+82-51-246-8668$ \\ E-mailvvoiceleebj@gmail.com
}

Carcinosarcomas, also known as true malignant mixed tumors, are rare tumors of the salivary gland and are composed of both malignant epithelial and malignant mesenchymal elements. They may occur in pre-existing pleomorphic adenomas or arise de novo. Here we report the first case of carcinosarcoma of the parotid gland composed of mucoepidermoid carcinoma and osteosarcoma. The tumor had originated from the parotid gland and extended into the parapharyngeal space. To the best of our knowledge, there have been no reports on mucoepidermoid carcinoma mixed with osteosarcoma ex pleomorphic adenoma in the parotid gland. Korean J Otorhinolaryngol-Head Neck Surg 2019;62(10):583-7

Key Words Carcinosarcoma - Mucoepidermoid carcinoma - Osteosarcoma P Parotid gland · Malignant mixed tumor.

\section{Introduction}

Carcinosarcomas are extremely rare tumors that are composed of both malignant epithelial and mesenchymal elements. The incidence accounts for $0.04-0.16 \%$ of all salivary gland tumors, and the parotid gland is the most common affected site. ${ }^{1,2)}$ They may arise in other major salivary glands such as the submandibular gland with pain and facial palsy. ${ }^{2,3)}$ Since Kirklin, et al. ${ }^{4)}$ described first in 1951, only approximately 60 cases have been reported until 2001. ${ }^{1)}$ The most common epithelial origin malignancy is known as squamous cell carcinoma or adenocarcinoma. The most common mesenchymal origin malignancy is known as chondrosarcoma,

This is an Open Access article distributed under the terms of the Creative Common Attribution Non-Commercial License (https://creativecommons.org/licenses/by-nc/4.0) which permits unrestricted non-commercial use, distribution, and reproduction in any medium, provided the original work is properly cited. followed by fibrosarcoma, leiomyosarcoma, osteosarcoma, and liposarcoma. ${ }^{3)}$

The parapharyngeal space is a pyramidal area containing both the pre- and poststyloid compartments. Tumor pathology in this area is based on these anatomic structures. We report a case of carcinosarcoma composed of mucoepidermoid carcinoma and osteosarcoma ex pleomorphic adenoma which originated from the deep lobe of the parotid gland and extended into parapharyngeal space.

\section{Case}

A 64-years-old woman presented with an enlarged mass in the left parotid gland for 2 months. She also complained of pain and facial palsy of the marginal mandibular branch. She was on medication for hypertension and hyperlipidemia, 
records of other surgical, family, and psychosocial histories were unremarkable.

On physical examination, a firm, immobile, and tender mass measuring $4 \times 4 \mathrm{~cm}$ was palpable in the left parotid region. The findings from the routine laboratory studies were within normal limits. Preoperative contrast-enhanced CT and MRI revealed a well-defined, heterogenous, lobulated mass $(6.6 \times$ $3.2 \mathrm{~cm}$ ) originating from the left parotid deep lobe and involving the left parotid, parapharyngeal, masticator, and carotid spaces (Fig. 1). A core-needle biopsy showed scattered giant cells in collagenous and chondroid stroma, consistent with a giant-cell lesion of the parotid gland.

After a thorough preoperative evaluation, the patient underwent left total parotidectomy with selective neck dissection (levels II and III) via the transcervical-parotid approach. A lateral neck incision was made just medially to the anterior margin of the sternocleidomastoid muscle, which extended to the level of the left parotid gland (Fig. 2). The tumor was completely excised, but the left facial nerve marginal mandibular branch had to be sacrificed because the tumor encased the nerve. After excision of the tumor, the left facial nerve marginal mandibular branch was grafted using the left greater auricular nerve.

Grossly, the tumor weighed $106.6 \mathrm{~g}$ and measured as $8.8 \times$ $5.7 \times 4.2 \mathrm{~cm}$ in size (Fig. 2). The cut surface revealed a yellowish white appearance with focal necrosis. Microscopically, the tumor was composed of 3 components: pleomorphic adenoma, mucoepidermoid carcinoma, and osteosarcoma. The myoepithelial component was observed as admixed with myxoid stroma, suggestive of pre-existing pleomorphic adenoma. The osteosarcoma component comprised malignant spindle cell proliferation with tumor giant cells and osteoid formation. The mucoepidermoid carcinoma component showed well-formed glands and mucin production (Fig. 3). The resection margin was positive for extraskeletal osteosarcoma. Twenty-four regional lymph nodes were all negative for the metastasis.

As a result of multidisciplinary meeting, it was decided that chemotherapy is proper than radiotherapy for resection margin positive osteosarcoma. The patient received 6 cycles of adjuvant chemotherapy containing doxorubicin and ifosfamide for the osteosarcoma component. Eighteen months
Fig. 1. Preoperative parotid CT scans and MRI. Axial (A) and coronal (B) CT scans, and T1- (C) and T2- (D) weighted images revealed a welldefined, heterogenous, lobulated mass $(6.6 \times 3.2 \mathrm{~cm})($ white arrow) originating from the left parotid deep lobe and involving the left parotid, parapharyngeal, masticator, and carotid spaces. CT: computed tomography, MRI: magnetic resonance images.
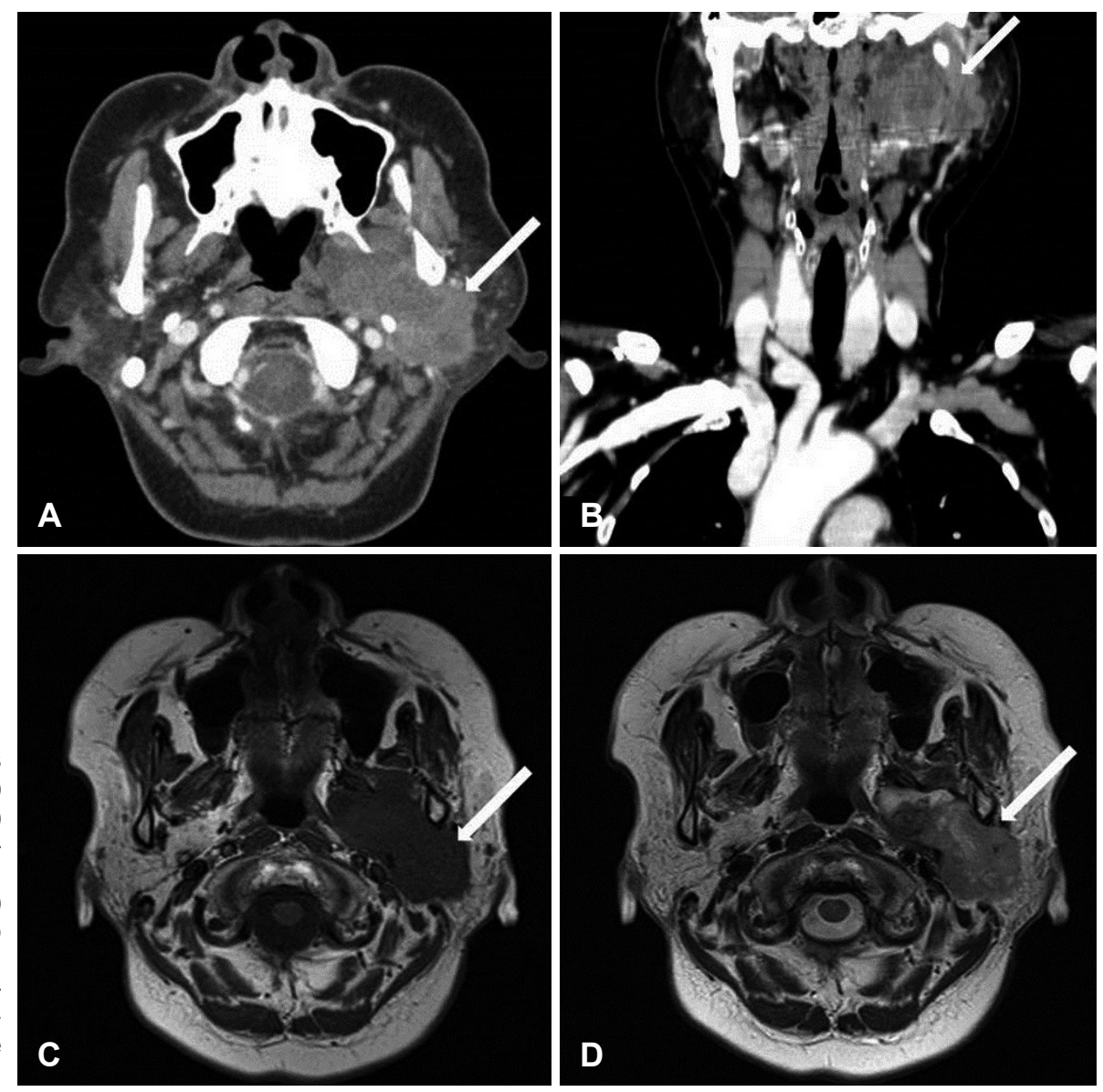
following the completion of the therapy, no disease recurrence was noted.

\section{Discussion}

The mixed carcinoma and sarcoma of the parotid gland was first described in 1951 by Kirklin, et al., ${ }^{4)}$ and the sarcoma- tous component was considered to be the stroma of the tumor. The term "true malignant mixed tumor" (carcinosarcoma), which refers to a tumor composed of carcinoma and sarcoma, was first used by $\mathrm{King}^{5)}$ in 1967.

Histogenesis and pathogenesis of carcinosarcoma are still being discussed. Vékony, et al. ${ }^{6}$ performed oligonucleotide microarray-based comparative genomic hybridization on the

Fig. 2. Intraoperative photograph. Incision line was designed for the transcervical-parotid approach. A lateral neck incision was made just medially to the anterior margin of the sternocleidomastoid muscle, which extended to the level of the left parotid gland (A). Resected mass was measured as $8.8 \times 5.7 \times 4.2 \mathrm{~cm}$ in size (B).
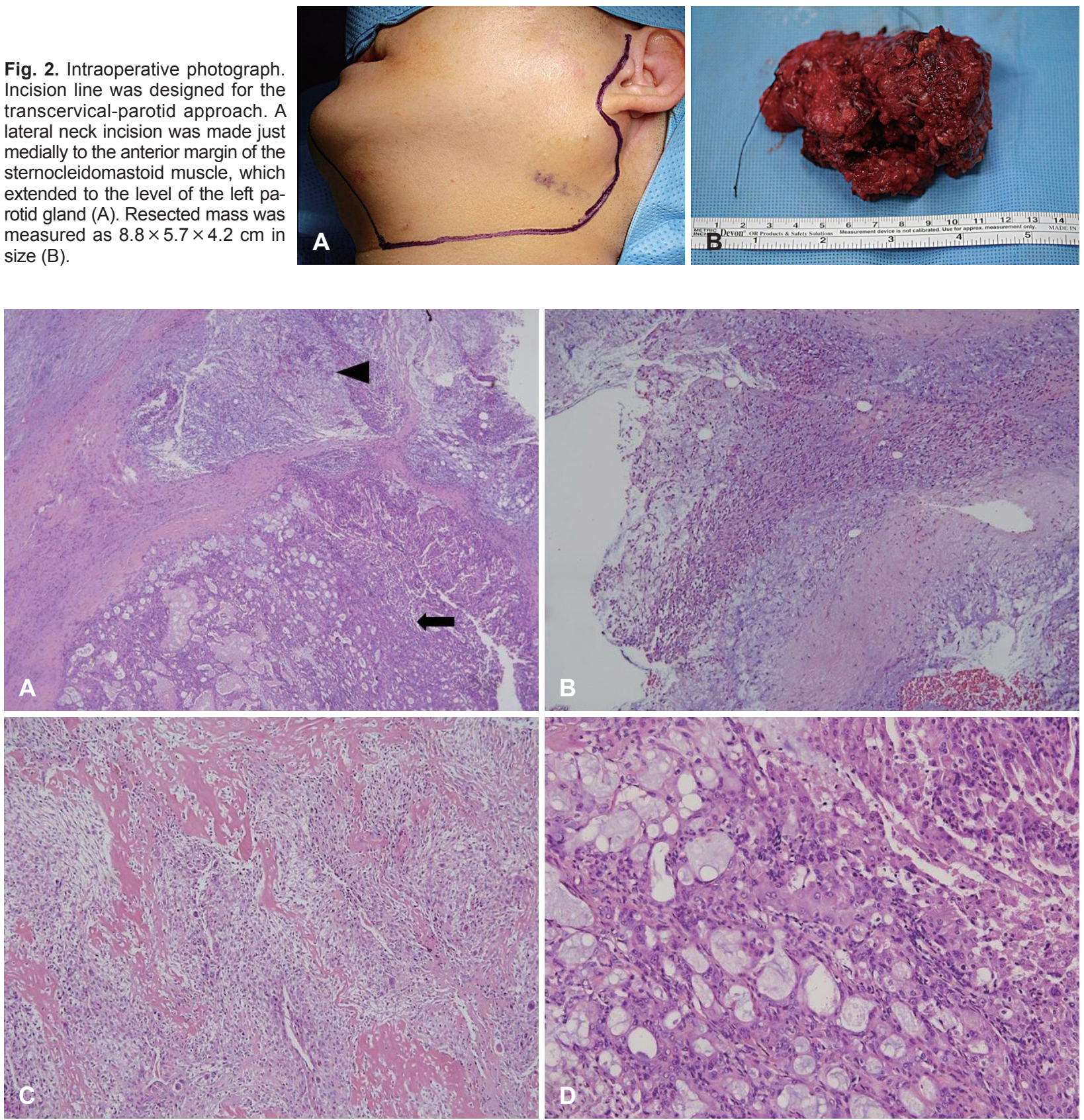

Fig. 3. Pathologic findings of the parotid mass. Pleomorphic adenoma (arrowhead) and mucoepidermoid carcinoma (arrow). Note the myxochondroid stroma of the pleomorphic adenoma and gland formation of the mucoepidermoid carcinoma $(\mathrm{H} \& \mathrm{E}, \times 40)(\mathrm{A})$. The pleomorphic adenoma component comprising the myoepithelial component is observed as admixed with myxoid stroma $(H \& E, \times 100)(B)$. The osteosarcoma component comprised malignant spindle cell proliferation with tumor giant cells and osteoid formation (H\&E, $\times 100)$ (C). Well-formed glands and mucin production of mucoepidermoid carcinoma (H\&E, ×200) (D). H\&E: hematoxylin and eosin. 
carcinoma and sarcoma components of carcinosarcoma. They found $75 \%$ homology in the DNA copy number profiles between the two components and concluded that the epithelial and mesenchymal elements in carcinosarcoma may have evolved from a single precursor cell. Clinical, histologic, and immunohistochemical studies indicate that carcinosarcoma and pleomorphic adenoma of the salivary gland can share common precursor cells, which means that the myoepithelial cell is a major component of development. However, it has been demonstrated that certain carcinosarcoma does not show evidence of myoepithelial cell origin or differentiation, and they have been shown to occur independently of pleomorphic adenoma."

Jha, et al. ${ }^{7)}$ introduced two main hypotheses for the de novo genesis of carcinosarcoma: collision and monoclone. The collision hypothesis is the development of two independent elements that are intermixed. The monoclonal hypothesis is more widely accepted and refers to a common precursor in the form of dedifferentiated or pluripotent cells that undergo divergent differentiation. The difference between the two theories is the coexistence of a typical pleomorphic adenoma and immunohistochemical positivity for S-100 and smooth muscle actin. It can suggest a carcinoma ex pleomorphic adenoma (CXPA). ${ }^{7,8)}$ Stodulski, et al. ${ }^{9)}$ classified three subtypes of pleomorphic adenoma that carry malignant traits: CXPA, carcinosarcoma (true malignant mixed tumor), and metastasizing pleomorphic adenoma. They described that the most common subtype is CXPA, and carcinosarcoma ex pleomorphic adenoma is known to be rare.

Only 12 cases of carcinosarcoma with osteosarcoma as the sarcomatous component have been reported. In the current case, we obtained the final pathologic result of mucoepidermoid carcinoma associated with osteosarcoma ex pleomorphic adenoma. Marcotullio, et al. ${ }^{2)}$ reported the first de novo mucoepidermoid carcinoma mixed with osteosarcoma in the submandibular gland. To the best of our knowledge, there have been no reports about mucoepidermoid carcinoma mixed with osteosarcoma ex pleomorphic adenoma in the parotid gland.

Mucoepidermoid carcinoma is a common salivary gland tumor derived from the ductal epithelium of the salivary gland, which displays various biological behavior patterns. The highgrade variant is more aggressive with a poor prognosis, whereas the low-grade variant usually demonstrates satisfactory survival rates. The diagnosis of mucoepidermoid carcinoma includes the identification of three intermixed tumor elements: mucin-producing cells, intermediate and/or clear cells, and squamoid cells.

Osteosarcomas are primary malignancies of the bone with rare extra-osseous head and neck localizations. Typical features of osteosarcomas are the presence of osteoid tissue within the neo-formation, with extremely pleomorphic cells included in the osteoid matrix.

Fine-needle aspiration cytology (FNAC) is not considered effective for the diagnosis of true malignant mixed tumors. Core-needle biopsy is a relatively new technique for the diagnosis of salivary gland masses that offer several potential advantages relative to FNAC. In our case, FNAC showed scattered giant cells in collagenous and chondroid stroma, consistent with giant-cell lesions of the parotid gland.

Because carcinosarcoma is an atypical and rare disease, there is no established treatment protocol yet. ${ }^{2)}$ Treatment may consist of surgery alone or surgery and postoperative radiotherapy. Staffieri, et al. ${ }^{10)}$ compared the carcinosarcoma recurrence data of a group of patients who underwent surgery alone versus those who underwent radiotherapy after surgery. The recurrence rate was lower after the combination of surgery and radiotherapy. Other sarcomas can be treated with surgery alone or surgery and postoperative radiotherapy. However, chemotherapy is an important part of the treatment for most cases of osteosarcoma. Most osteosarcomas are treated with neoadjuvant and adjuvant chemotherapy. There is no established treatment protocol for carcinosarcoma because of the lack of data on long-term treatment outcome, however the treatment method should be determined according to the histopathologic type. In our case, as a result of multidisciplinary meeting, it was decided that chemotherapy is proper adjuvant therapy for resection margin positive osteosarcoma. The patient received 6 cycles of adjuvant chemotherapy. During 18 months of follow-up, no disease recurrence was noted. However, this time is not sufficient to consider disease-free survival in our patient.

MRI with a perfusion image is useful for follow-up of carcinosarcoma patient after proper treatment. MRI is commonly used to confirm of tumor recurrence, however, differentiating between recurrent tumor and nonneoplastic contrastenhancing tissue is often challenging with conventional MRI. ${ }^{11,12)}$ Although 18F-fluorodeoxyglucose(FDG) PET and MR perfusion were effective to distinguish between tumor recurrence and nonneoplastic contrast-enhancing tissue, MR perfusion was more accurate than 18F-FDG PET. ${ }^{13)}$

Pleomorphic adenomas could progress to malignancy, as 
not only CXPA, but also as carcinosarcoma ex pleomorphic adenomas, like that observed in this case. Mucoepidermoid carcinoma associated with osteosarcoma of the submandibular gland has been reported previously. However, there have been no reports about mucoepidermoid carcinoma mixed with osteosarcoma ex pleomorphic adenoma in the parotid gland. Surgical excision would be the best treatment, but if the tumor cannot be completely resected by surgery, additional radiotherapy or chemotherapy should be considered.

\section{Acknowledgments}

This work was supported by a 2-Year Research Grant of Pusan National University.

\section{ORCID}

Hyun-Keun Kwon

Sung-Chan Shin

https://orcid.org/0000-0003-4089-8639

Jin-Choon Lee

https://orcid.org/0000-0003-2329-0648

https://orcid.org/0000-0002-4056-8763

Byung-Joo Lee

\section{REFERENCES}

1) Kwon MY, Gu M. True malignant mixed tumor (carcinosarcoma) of parotid gland with unusual mesenchymal component: A case report and review of the literature. Arch Pathol Lab Med 2001;125(6):812-5.

2) Marcotullio D, de Vincentiis M, Iannella G, Cerbelli B, Magliulo G. Mucoepidermoid carcinoma associated with osteosarcoma in a true malignant mixed tumor of the submandibular region. Case Rep Otolaryngol 2015;2015:694684.

3) Gnepp DR. Malignant mixed tumors of the salivary glands: A review.

Pathol Annu 1993;28 Pt 1:279-328.

4) Kirklin JW, McDonald JR, Harrington SW, New GB. Parotid tumors; histopathology, clinical behavior, and end results. Surg Gynecol Obstet 1951;92(6):721-33.

5) King OH Jr. Carcinosarcoma of accessory salivary gland. First report of a case. Oral Surg Oral Med Oral Pathol 1967;23(5):651-9.

6) Vékony H, Leemans CR, Ylstra B, Meijer GA, van der Waal I, Bloemena E. Salivary gland carcinosarcoma: oligonucleotide array CGH reveals similar genomic profiles in epithelial and mesenchymal components. Oral Oncol 2009;45(3):259-65.

7) Jha V, Kolte S, Goyal S, Mandal AK. Osteosarcoma arising in carcinosarcoma de novo parotid gland in a young man: An unusual case with review of literature. J Clin Diagn Res 2017;11(4):ED08-10.

8) Sironi M, Isimbaldi G, Claren R, Delpiano C, Di Nuovo F, Spinelli M. Carcinosarcoma of the parotid gland: cytological, clinicopathological and immunohistochemical study of a case. Pathol Res Pract 2000; 196(7):511-7.

9) Stodulski D, Rzepko R, Kowalska B, Stankiewicz C. Carcinoma ex pleomorphic adenoma of major salivary glands--a clinicopathologic review. Otolaryngol Pol 2007;61(5):687-93.

10) Staffieri C, Marioni G, Ferraro SM, Marino F, Staffieri A. Carcinosarcoma de novo of the parotid gland. Oral Surg Oral Med Oral Pathol Oral Radiol Endod 2007;104(2):e35-40.

11) Dooms GC, Hecht S, Brant-Zawadzki M, Berthiaume Y, Norman D, Newton TH. Brain radiation lesions: MR imaging. Radiology 1986; 158(1):149-55.

12) Mullins ME, Barest GD, Schaefer PW, Hochberg FH, Gonzalez RG, Lev MH. Radiation necrosis versus glioma recurrence: Conventional MR imaging clues to diagnosis. AJNR Am J Neuroradiol 2005;26 (8):1967-72.

13) Kumar Y, Gupta N, Mangla M, Hooda K, Mangla R. Comparison between MR perfusion and 18F-FDG PET in differentiating tumor recurrence from nonneoplastic contrast-enhancing tissue. Asian Pac J Cancer Prev 2017;18(3):759-63. 